\title{
Sickness and Death: Economic Consequences and Coping Strategies of the Urban Poor in Bangladesh
}

\author{
Farid Khan a,b, Arjun S. Bedi ${ }^{c}$, Robert Sparrow ${ }^{\mathrm{d}}$ \\ ${ }^{a}$ Curtin University, Perth, Australia. \\ ${ }^{b}$ University of Rajshahi, Bangladesh \\ ${ }^{c}$ Erasmus University Rotterdam, The Hague, The Netherlands. \\ ${ }^{d}$ Australian National University, Canberra, Australia.
}

\begin{abstract}
Published in World Development 72, August 2015, pp. 255-266 doi:10.1016/j.worlddev.2015.03.008
\end{abstract}

\begin{abstract}
We investigate the economic consequences of sickness and death and the manner in which poor urban households in Bangladesh respond to such events. Based on panel data we assess the effects of morbidity and mortality episodes on household income, medical spending, labour supply and consumption. We find that despite maintaining household labour supply, serious illness exerts a negative effect on income for the poor. However, the estimates do not reject consumption smoothing. The most prominent responses to finance current needs are increasing household debt through borrowing and depleting productive assets, both of which have detrimental effects on future consumption.
\end{abstract}

Keywords: sickness, death, consumption smoothing, coping strategies, Bangladesh, Asia.

Correspondence: Robert Sparrow, Arndt-Corden Department of Economics, Crawford School of Public Policy, Australian National University, Coombs Building 9, Fellows Road, Canberra, ACT 2601, Australia. Phone: +61-2-61253885.

Email: robert.sparrow@anu.edu.au.

Acknowledgements: We thank participants at the World Congress on Health Economics 2013 in Sydney and Zelalem Debebe for useful comments. Nirob Khandaker, Nazmus Sakib and Newaz Mostafa provided invaluable research assistance for the fieldwork. We are grateful to the International Food Policy Research Institute (IFPRI) for providing access to the data used in this paper. 


\section{Introduction}

In recent years, the economic consequences of episodes of morbidity and mortality in developing countries have received increasing academic and policy attention (for instance, Gertler and Gruber 2002, Asfaw and von Braun 2004, McIntyre et al. 2006, Wagstaff 2007, Gertler et al. 2009, Genoni 2012, Sparrow et al. 2014). In the absence of health and life insurance, serious illnesses or the death of a family member are likely to push vulnerable households who rely heavily on their labour, deeper into penury. Households experiencing unexpected bouts of illness or the death of a family member are likely to incur income losses to the extent that they rely on wage income and at the same time be forced to spend a larger fraction of their household budget on health care. To cope with such events and maintain consumption, households may liquidate assets, resort to intra-household labour substitution, borrow or withdraw children from school with potentially deleterious consequences for future household welfare. ${ }^{1}$

In one of the earliest studies to investigate the economic effects of illnesses, Townsend (1994), based on ICRISAT panel data from rural India, concluded that after controlling for village-level consumption, an idiosyncratic shock such as illness measured by the percentage of the year that an adult male was sick, had no effect on household consumption. Using the same data base Kochar (1995) found that the illness of a male household member especially during the peak period of the agricultural cycle was associated with a decline in wage income and increased informal borrowing. Taken together, these two studies suggest that while households may be able to retain consumption at least in the short run, this may come at the risk of future impoverishment. It also highlights the importance of jointly analysing the effects of illnesses on income, consumption and coping strategies. 
In general, the evidence on household ability to insure consumption against illhealth is mixed. In a nuanced analysis that supports a distinction between minor and more severe illnesses, Gertler and Gruber (2002) use a large panel data set from rural Indonesia to show that while households are able to insure consumption against 70 percent of high-frequency minor illnesses, they are able to protect themselves against only 30 percent of low-frequency illnesses that limit the physical functioning of family members. Also based on data from Indonesia, Gertler et al. (2009) and Nguyen and Mangyo (2010) conclude that households are unable to protect their consumption against large health shocks and chronic illnesses. In contrast, Genoni (2012) finds no evidence of imperfect consumption smoothing in Indonesia while Sparrow et al. (2014) report that it is only informal sector workers and the poor who are unable to protect their consumption. Studies for other countries that show that households are only partly able to smooth consumption, especially in the event of large infrequent shocks and chronic illness, include Dercon and Krishnan (2000) and Asfaw and Braun (2004) for Ethiopia, and Wagstaff (2007) for Vietnam, whereas Mohanan (2013) finds little evidence of imperfect smoothing in India and De Weerdt and Dercon (2006) find evidence of consumption smoothing through networks in Tanzania. Pertinent to the current context, based on panel data from rural Bangladesh, Skoufias and Quisumbing (2005) find no effect of male or female illnesses on household consumption. While, in a more recent paper, also based on panel data from rural Bangladesh, Islam and Maitra (2012) report that consumption smoothing is imperfect in the case of a large shock.

While there are several reasons for the differences in the degree of consumption smoothing reported across studies, of primary concern in the relatively recent papers in this genre (e.g. Wagstaff 2007; Genoni 2012, Mohanan 2013, 
Sparrow et al. 2014) are the transmission channels through which ill-health and mortality affect consumption and identification of the strategies adopted by households to maintain consumption. Indeed, the effects of mortality and morbidity on current consumption and the ability of households to (partially) maintain consumption may be a misleading indicator of the economic impacts of such events, especially if consumption is maintained through incurring high-cost debt (e.g. Mohanan 2013; Ambrosius and Cuecuecha 2013), selling assets (e.g. Islam and Maitra 2012) or foregoing human capital investments in children (Mottaleb et al. 2015). Echoing this view, Chetty and Looney (2006) argue that focusing on the effect of a shock on consumption is not very informative without determining why and how households smooth consumption.

This paper uses data from urban Bangladesh to add to the relatively thin literature which explores the transmission channels, coping responses and economic consequences of mortality and morbidity episodes. In the Bangladeshi context, a number of studies (Carrin et al. 1999, Kabir et al. 2000, Begum and Sen 2004) have examined the effects of illnesses on the livelihoods of rickshaw pullers and more generally the urban poor. These studies suggest that ill health is the single most important factor influencing the (downward) economic mobility of households. However, while these papers yield useful insights they do not establish causal effects of health shocks on economic outcomes.

Our empirical analysis relies on longitudinal data and examines the effect of serious illnesses and the recent death of a household member on medical expenditure, income, labour supply and consumption. An assessment of the effect of health shocks on these various outcomes, as opposed to focusing only on the overall effect on consumption, is likely to provide insights on the channels through which health 
shocks affect households. We also study the strategies adopted by households to deal with shocks and subsequently investigate the effect of the most commonly used coping strategies on future consumption.

An additional novelty is the focus on urban households as compared to the bulk of the literature which deals with such issues in a rural context. ${ }^{2}$ It is likely that due to factors such as differences in occupation and access to informal credit, rural and urban households react differently to different types of shocks. A review of studies which have examined the effects of various shocks, albeit not health shocks, suggests that rural households are more vulnerable to covariate shocks while urban households display greater vulnerability to idiosyncratic shocks (see Günther and Harttgen 2009).

With regard to health shocks in the Bangladesh context, Begum and Sen (2004) and BBS-UNICEF (2010) argue that given their occupations which may be physically more demanding, on average smaller household size, less flexible working arrangements and less extensive social networks, urban slum households may be more vulnerable to health shocks as compared to rural households and at the same time may be less able to access informal sources of credit. Furthermore, as shown in BBSUNICEF (2010), in Bangladesh, due to the concentration of various government and NGO human development programmes in rural areas, the urban poor, especially those residing in urban slums, have lower access to basic services which may also make them more vulnerable to health shocks as compared to their rural counterparts. While we cannot offer a comparative analysis of the effects of health shocks on rural and urban households, which is a drawback, we contribute by providing, to the best of our knowledge, the only study that quantifies the economic risk from morbidity and mortality specifically for poor urban households. 
The paper is organised as follows: Section II outlines the setting and the data while section III lays out the empirical framework. Section IV discusses the results while section V summarizes and concludes the paper.

\section{The setting, data and descriptive analysis}

The setting

According to the latest available figures, Bangladesh is one of the most densely populated countries in the world (1111 individuals per square kilometre) with 27 percent of its 160 million population living in urban areas. Driven by the rapid inflow of rural migrants due to poverty and environmental reasons, urban population growth (3.5 percent per annum between 2005-2010) far outstrips the corresponding figure for rural areas (1 percent), contributing to the growth of slums. An estimated 60 percent of the urban population lives in slums. ${ }^{3}$ At a national level, health facilities are limited with 0.6 hospital beds and 0.4 registered physicians per thousand persons in 2011 which is substantially lower than other developing countries. ${ }^{4}$ Insurance coverage is almost non-existent and in 2011, out-of- pocket payments accounted for about 96.6 percent of private health expenditure..$^{5}$

This study is set in the slums of Dinajpur, a city of about 270,000 residents located in the north-western region of Bangladesh, about 400 kilometres from Dhaka. The town consists of 80 communities of which 59 are classified as slum communities. The slum communities are integrated into the city and slum-dwellers are typically engaged in the informal sector and in occupations such as trading and hawking, domestic work, rickshaw pulling, brick breaking and construction. In terms of government health facilities, the town has a 500 bed public general hospital. In 
addition, there are a large number of pharmacies, private clinics and diagnostic centres as well as a range of religious and spiritual healers.

\section{Data}

This study relies on data from the SHAHAR (Supporting Household Activities for Health, Assets, and Revenue) Dinajpur Survey which was conducted in slums and low-income settlements within the municipal areas of Dinajpur in 2002 and 2003 by CARE-Bangladesh and the International Food Policy Research Institute (IFPRI). Based on observed levels of poverty, social cohesion, community size, and environmental hazards, the 59 slum communities in Dinajpur were assigned a vulnerability score. Of these, fourteen slums with a high vulnerability score were selected for an intervention by CARE. Based on power calculations, a simple random sample of 614 households was drawn from the selected slums. The sample represents about 60 percent of the overall slum population of Dinajpur (for details, see Buttenheim 2008). ${ }^{6}$

Three survey rounds were conducted with the first round taking place in July and August 2002 followed by round 2 in March 2003 and round 3 in August and September 2003. These three survey rounds were combined to create a panel data set. In the first round, enumerators successfully contacted and interviewed 585 households or 95 percent of the desired sample of 614 households. In the second round, data were collected from 567 households (92 percent of the original sample, 97 percent of the first round households) and in the final round 553 households (90 percent of the original sample, 95 percent of the first round households). A sample attrition rate of 5 percent is quite small, suggesting that the data are unlikely to be afflicted by attrition bias. More formally, based on data from the first round, a probit regression with drop 
out as the dependent variable indicates that except for household size there is no systematic difference in various observed characteristics between households who drop out from the sample and those who remain. Most notably there is no evidence that the incidence of morbidity or mortality is systematically linked to dropping out from the sample. ${ }^{7}$

The surveys gathered information on household composition, education, employment, savings and credit, household food and non-food consumption, assets, and most pertinently for this paper - on various shocks affecting households, their financial consequences and household responses to these shocks.

To complement the quantitative data, in July 2010, qualitative information was collected in six of Dinajpur's slum communities. The aim was to explore and understand household conceptualization of health shocks and the manner in which households deal with such events. Data gathering approaches included semistructured interviews with 11 households (selected based on variation in terms of age, occupation, and gender) who had experienced a recent morbidity or mortality event, three focus group discussions of five to seven individuals and interviews with five key informants (a traditional healer, an NGO official, hospital nurse, health worker and community leader).

\section{Descriptive analysis - shocks and coping}

The survey solicited information on 26 different types of shocks that may affect households. Across the three survey rounds, about 32 percent of the total householdobservations indicate the presence of a shock. While households face an array of shocks, by far the most common (49 percent) is a serious illness - an illness which prevents a household member from undertaking normal activities - in the last one year (see Table 1). The death of a household member accounted for about 8 percent of the 
shocks. ${ }^{8}$ Specifically with regard to sickness and death, 168 households report a health shock in round 1 , while in rounds 2 and 3, the number of households reporting such events appears to decline sharply to 58 and 82 households (see Table 2). However, since rounds 2 and 3 were conducted six months after the preceding surveys, in practice the responses to the mortality and morbidity questions in rounds 2 and 3 cover the six month period preceding the previous survey rather than the longer recall periods used for the first round. Overall, over the three panel waves, the sampled households reported 308 incidents (or about 18 percent of all observations) of a death or serious illness/injury. While the incidence of mortality and serious morbidity may seem high, given the nature of the sample - urban slum dwellers and their often physically demanding occupations - this is probably not surprising. Kabir et al. (2000) in their analysis of slum dwellers in Dhaka find that 40 percent of sampled individuals reported some kind of illness (i.e. minor and serious) in the past 14 days. Similarly, in their work on rickshaw pullers in Dhaka, Begum and Sen (2004) report a morbidity rate of 11.4 percent on the day of the survey and 39 percent over a period of one month, rates which they claim are higher than that for the rural poor. Islam and Maitra (2012) find that 21 percent of households in the rural Bangladesh in 2004-2005 survey reported an episode of illness in the past 15 days.

The survey then follows on by inquiring about the most important manner in which households react to the costs associated with morbidity and mortality. At 39 percent, the most prominent response is 'none' (see Table 3). Since the measure of morbidity is any illness that prevents an individual from engaging in normal activities and is not sensitive to the duration of the event, no-response may reflect illnesses of short duration which did not have particularly onerous financial implications. In terms of a more active response, the most common approach is to resort to borrowing from a 
money lender (about 31 percent) followed by depleting assets or savings (8.4 percent), borrowing from NGOs (6.8 percent) and taking help from their social network (5.8 percent). This is in line with Kabir et al. (2000) who also find that that taking a loan is the most common response to cope with illness induced costs amongst slum dwellers in Dhaka. They further report that the sale of productive assets is much less common than borrowing, while savings are limited and do not provide adequate support in case of a serious illness. The semi-structured interviews confirmed this pattern, with the respondents pointing out that while borrowing from money lenders at annual average interest rates ranging from 30 to 200 percent is not a preferred option, it is the most widely used response. The use of this potentially harmful coping option highlights the limited access to formal sources of credit and restricted social network, at least with regard to finance, of slum dwellers.

Table 4 presents the means and standard deviations of some of the key variables. The sampled households are relatively poor compared to national patterns. In the first survey round 60 percent of the households reported total expenditure that, per capita, falls below the 2000 urban poverty line. ${ }^{9}$ To place this in a national perspective, Sen (2003) estimates an urban (rural) poverty headcount of 26 (44) percent in $2000 .{ }^{10}$ A typical sample household is headed by a 43 year old male ( 87 percent) and has 4 to 5 members. Educational attainment is low with only about 16 percent of the heads having completed at least primary school. On average a household supplies 80 to 100 hours of labour per week or about 21 hours per capita. Depending on the survey round, unearned income contributes to between 6 to 11 percent of per capita total monthly income. The main sources of this unearned income are transfers, social assistance, leasing property or selling assets. Health expenditure accounts for 5 to 6 percent of total household spending, with about 10 percent of 
households allocating more than 15 percent of their budget to health care. The bulk of household income is spent on food which accounts for between 50 to 56 percent of total non-medical spending. The total reported value of household assets is more than twice that of average annual per capita income. About a quarter of total household assets can be regarded as productive assets. ${ }^{11}$ In the first round, loans amount to 54 percent of per capita annual income while in rounds 2 and 3, the debt-burden appears to have increased with loans amounting to 72 to 80 percent of per capita annual income. The unsustainability of borrowing from money lenders and the consequences of such a strategy were clearly amplified during field work. For instance, one of the key informants, a male 40 year old male community leader, reported that at times households flee in order to escape harassment from money lenders. Additionally, in one of the eleven case studies, a 45 year old male respondent stated:

'After repaying monthly interest instalment I cannot afford my family. I have sent my daughter to her grandparent's house to reduce food and education expenses. It is giving us so much pain and worries like a slow poisoning. I do not see any hope escaping from this vicious trap in near future. Sometimes I wish we head down together to the railway.' [Interview conducted on July 23, 2010].

In a number of the 11 case studies, while households mentioned that they were able to borrow to meet their immediate needs, this was followed by withdrawal of children from school and their induction into the labour force. For instance a 32 year female respondent narrated that her mother-in-law had been suffering from severe illnesses for one and a half years, which had led to a huge debt burden due to treatment costs. After meeting consumption expenses and repaying the monthly loan instalment, the earnings from her husband's rickshaw pulling are insufficient to pay 
for the medical expenses and education expenses for her son. Consequently, her nine year old son began working as a shop assistant. Similarly, the son of a 45 year old female respondent narrated,

'I cannot go to school regularly after my mother's illness, because I have to cook and take care of her. Currently, I am working in a nearby mosque to clean and carry orders of Imam (religious leader) of the mosque where my father used to work.' [Interview conducted on July 24, 2010].

\section{Methods}

Our empirical analysis assesses (i) the channels of economic risk of morbidity and mortality for households, (ii) the ability to smooth consumption when faced with these risks, (iii) the coping strategies adopted to deal with morbidity and mortality, and (iv) the dynamic effects of using borrowing or depleting assets as a coping response.

\section{Income and consumption}

We first test whether morbidity and mortality have a causal effect on per capita household income (earned and unearned) and out-of-pocket (OOP) health care spending in the last month, the incidence of catastrophic OOP health care spending (indicating whether a household spent more than 15 percent of its total consumption on health care), and per capita household food and non-food consumption net of medical spending.

The consumption, income and OOP related outcome variables have a typically skewed and non-normal distribution censored at zero, which makes linear models such as ordinary least squares unsuitable. We therefore use a fixed effects Poisson 
model (FEP) in order to deal with these distributions and also avoid retransformation problems of taking natural logs of the outcome variables (Manning and Mullahy 2001, Buntin and Zaslavsky 2004, Mihaylova et al. 2011, Sparrow et al. 2014). An advantage of using a FEP model is that the outcome variable does not actually need to follow a Poisson distribution; the FEP estimator is consistent under the assumption that the conditional mean is correctly specified (Santos Silva and Tenreyro 2006, Wooldridge 2002). For the outcome variables per capita household income and expenditure we specify the conditional mean as:

$$
E\left(y_{i t} \mid h_{i t}, x_{i t}, \theta_{c t}, \alpha_{i}\right)=\exp \left(h_{i t}^{\prime} \beta+x_{i t}{ }^{\prime} \gamma+\theta_{c t}+\alpha_{i}\right)
$$

The vector of the main ill health variables of interest $\left(h_{i t}\right)$ includes morbidity and mortality indicators for household $i$ in survey wave $t$. Morbidity is defined as serious illness or injury of a household member, while the mortality variable combines death of a main earners and that of any other household member (as it is reported in Table 2). The $\beta$ coefficients can be interpreted as a percentage change in $y$ due to a unit change in the morbidity and mortality indicators. We further include time and community interacted fixed effects $\left(\theta_{c t}\right)$ to capture covariate trends in income and expenditure, and household fixed effects $\left(\alpha_{i}\right)$. The association between self-reported ill health and the outcome variables could be misleading as a causal effect if there are unobserved characteristics driving the relationship. For example, an individual's perception of one's health status will affect self-reporting of illness but might itself be affected by socio-economic factors. The households fixed effects control for such unobserved confounders since these are typically time invariant. In addition, a vector of household characteristics $\left(x_{i t}\right)$ controls for important time variant 
characteristics, such as household size, the demographic profile and a set of nonhealth related yet potentially confounding self-reported shocks (loss of crops and livestock, loss of assets, bankruptcy and other shocks).

Two empirical problems remain that are not explicitly addressed by the fixed effects strategy. First, the fixed effects estimates will be biased if the vulnerability to morbidity and mortality is directly affected by a change in consumption. However, such a relationship is typically a long run phenomena and unlikely to be observed over the relatively short intervals of the Dinajpur survey waves. Moreover, this bias would cause the coefficients to overestimate the effects of morbidity and mortality and increase the probability that the null hypothesis of consumption smoothing will be rejected. As the next section will show, we do not observe this in the estimation results. A second potential problem is state dependence, which occurs when preferences are affected by changes in health status. In this case any observed correlation between morbidity and consumption could be due to shifting preference rather than the economic impacts of morbidity. Unfortunately we were not able to test for state dependence. However, other studies of ill health events that are able to test do not find evidence of state dependence (see, for example, Gertler and Gruber 2002, Gertler et al. 2009, Sparrow et al. 2014). ${ }^{12}$

\section{Coping strategies}

To assess the role of coping strategies for smoothing consumption in response to shocks, we investigate relationship between shocks and coping responses, and why households choose a particular coping response over another.

The various self-reported coping strategies (see Table 3) used by households to deal with mortality and morbidity are grouped into four aggregate categories. These 
are depleting assets and savings, borrowing, other strategies and none. In addition, we consider labour supply adjustments (per capita hours worked by household members in the past seven days) and changes in the value of assets, both productive and consumer durables, as potential outcomes that may be affected by coping behaviour. Finally, we use the debt-to-income ratio (total outstanding debt at the time of the interview as a ratio of income in the last month) as a measure of the severity of indebtedness.

Which coping strategies do household choose in response to mortality and morbidity? The questions for the self-reported coping strategies are asked contingent on a respondent reporting a specific shock (see Table 1 for the various shock types). While the type of coping strategy reported per shock is mutually exclusive, the coping response variables that we consider here are not, because households may face multiple shocks during the same recall period. We argue that in case a household faces multiple shocks, one particular shock will not only induce an immediate response but will also affect households' options for responding to other shocks, for example by tightening the budget constraint or diminishing buffers. We therefore generate binary variables that indicate whether households have relied at least once, in any of the three panel waves, on each of the four aggregate coping strategy categories, irrespective of the type of shock. We then run regressions for each coping strategy to assess to what extent these are invoked in response to morbidity and mortality, restricting the sample to an unbalanced panel of those observations where any shock was reported in the respective survey round. Since labour supply, asset value and the debt-to-income ratio also follow skewed and censored distributions, we apply the FEP specification presented in equation (1). However, self-reported coping response variables (depleting assets and savings, borrowing, other) are binary, in which case 
we use a linear probability model with household fixed effects. The linear probability models include the same control variables and time-community interaction terms as the FEP models. ${ }^{13}$

Given that households are faced by a specific shock and have an option of a range of possible coping strategies, what determines the eventual choice of strategy? We can observe this by going back to the original information on the main coping response per reported shock, and then focussing solely on morbidity. As explained earlier, these self-reported coping strategies are mutually exclusive for each type of shock, which would justify a multinomial logit estimation of the determinants of coping responses to serious illness (there are too few reported deaths to allow a separate analysis of the coping response to mortality). However, this approach implies a few caveats and we have to be careful interpreting these estimates as causal effects. We cannot control for household fixed effects in the multinomial logit and therefore cannot control for any unobserved heterogeneity. We also had to drop the community fixed effects for the model to converge.

Finally, to test for dynamic effects of incurring debt and depleting assets, we estimate the effects of changes in the debt-to-income ratio and the value of productive assets on future per capita household consumption. We do this re-estimating the FEP model in equation (1) for food-, non-food- and total consumption, and including the one-period lagged debt-to-income ratio and value of productive assets as additional explanatory variables.

\section{Results}

Income and consumption 
The effects of morbidity and mortality of a household member on measures of economic risk - medical spending and income loss - are shown in Table 5. Serious illness increases per capita OOP health spending by 96 percent and OOP as a share of the household budget by 66 percent. This increase in average medical spending also includes some potentially impoverishing health spending events, as the incidence of catastrophic health spending increases by 15 percentage points. As may be expected, the death of a household member does not affect OOP medical spending. We see an opposite pattern for income loss. On average, income is not affected by illness, while the recent death of a household member does reduce per capita earned income by about 30 percent. $^{14}$

Serious illness increases OOP health spending irrespective of the level of wealth, and these effects are similar in magnitude to the average effects for the full sample (Table 5). We divide the sample into the poorest and wealthiest 50 percent based on per capita household (non-medical) expenditures in the first round of the survey. The effects on health spending and catastrophic spending incidence are slightly larger for the wealthiest half of the sample, but the differences between the groups are not statistically significant.

However, we do see considerable differences for the poorest and wealthiest halves of the sample with regard to income loss. For households among the poorest 50 percent, serious illness leads to a loss of monthly earned income of 11 percent. A death of a household member is associated with a negative coefficient for earned income, also translating to an 11 percent reduction, although this estimate is not precise. In contrast, unearned income for this group increases by 133 percent as a result of the death of a household member, possibly due to sales of assets or receiving remittances and informal transfers through social networks. There is some evidence of 
this from the qualitative interviews, which also feature anecdotes of local communities and family members collecting donations from local markets, a nearby railway station and bus stops, and local mosques for funeral assistance. For instance, a neighbour of a 12 year old girl who lives with her two younger brothers and who had lost her mother a month before the interview stated,

'Her father is physically disabled. He begs on the street and sleeps on railway platform. Her mother was the only earning member in the house. At the time of her death, she left almost nothing - no money; no foods - except a small shanty. We collected some donation for her funerals and gave it to her (the girl) for their livelihoods.'[Interview conducted on July 23, 2010].

For the wealthiest half of the sample we see that a death in the household reduces earned income by 41 percent and total income by 40 percent, but we find no effects of serious illness on income. Many of the households in this subsample are involved in small trading, such as street peddlers with a fixed location and petty trade. These mostly informal trade practices operate with the help of household members, which may also provide income protection in case of serious illness of other household member. A small fraction of households also rely on income from formal sector employment, such as low-grade employees with government and semigovernment organisations, which provide some income protection. ${ }^{15}$

So far, at least for the sample as a whole (Table 5), we see that morbidity leads to a sharp increase in spending on health care and mortality leads to a large decline in earned income. Despite these negative effects, irrespective of wealth level (Table 5) we find that households manage to smooth their food and non-food consumption when faced with serious illnesses. Consumption levels for the poor are not affected by 
the lost earned income when a productive household member dies, most likely due to the offsetting effects of (informal) transfers (Table 5). Interestingly, we see that the death of a household member actually increases per capita non-food consumption for the wealthiest half of the sample, presumably because household non-food consumption is not easily reduced in the short term, while the number of household members is reduced.

\section{Coping strategies}

How do households manage to maintain their consumption levels despite the sharp increases in medical spending and reductions in income? Borrowing and depleting assets and savings are the two key coping strategies in dealing with the economic risk of ill health (Table 6). The incidence of serious illness increases the probability of borrowing by 61 percentage points and the debt-to-income ratio by 38 percent. The effect emanates mainly from the less-wealthy households where the incidence of serious illness increases the probability of borrowing by 76 percentage points and the debt-to-income by 62 percent. Serious illness also sparks a depletion of assets and borrowings. For the sample as a whole, serious illness increases the probability of depleting assets by 27 percentage points. Once again, the effect is much larger for the poorer half of the sample although the estimates are not precise. Nevertheless, consistent with the increase in the probability of asset depletion, for poorer households a serious illness reduces the value of productive assets of 42 percent. The estimates show that selling productive assets is a more effective way of raising additional revenue as compared to selling consumer durables. The qualitative interviews provide anecdotes that are in line with this finding, as some households reported selling productive assets such as livestock, poultry, or even a rickshaw to 
meet medical expenses and smooth consumption. While selling such assets protects current consumption it is likely to have a negative bearing on future earnings capacity and future consumption. Illness is also associated with an increase in borrowing and asset depletion amongst wealthier households but the effects are statistically imprecise.

For less-wealthy households, the death of a family member increases both the probability of borrowing, by 54 percentage points, and depleting assets and savings, by 38 percentage points. However, there are no discernible changes in the debt-toincome ratio or on asset values. For the wealthiest half, we find no clear evidence of borrowing or depleting assets and savings as coping strategy. There is a negative effect of mortality on labour supply, which can be explained by the loss of an economically active household member.

The determinants of the choice of coping strategy given that a household reported a serious illness are presented in Table 7 . The table shows marginal effects based on multinomial logit estimates where we included the coping strategy option "none" as an additional category to complete the full set of options. ${ }^{16}$ The results show little variation in household characteristics across the four strategies, except for education of the household head. Increasing education, especially beyond completing primary school, increases the probability of borrowing or having no specific response, instead of depleting assets. These results are not driven by differences in budget constraints, since we control for per capita consumption quartiles. ${ }^{17}$ The most probable explanation is that higher educated households have better awareness and access to (informal) financial markets. Educated household heads are more likely to be members of local money deposit associations (locally known as Samity) and maintain social networks that increase access to credit. Wealthier households, on the 
other hand, are more likely to sell assets in response to shocks, as for such households assets are likely to be relatively abundant.

\section{Dynamic effects of coping behaviour}

While borrowing and selling assets may seem successful coping strategies for the poor to smooth consumption, there may be long term implications of incurring debt and depleting productive assets. We find indirect evidence suggesting that these long term effects of health related borrowing and asset depletion are indeed a concern. Table 8 shows estimates of the effects of changes in the debt-to-income ratio and the value of productive assets on future consumption. We included productive assets rather than total assets, since productive assets are more relevant for future earnings capacity.

Both increasing debt and reducing productive assets have a statistically significant negative effect on future non-food consumption. Per capita non-food and total consumption decrease by 1.5 to 0.9 percent if total outstanding debt 6 months earlier increases by an amount equal to monthly household income. The productive assets coefficients translate to a decrease in per capita non-food and total consumption of 1.7 and 1.3 percent if the value of productive assets would decrease by a value equal to lagged mean monthly household income. These effects are slightly larger than for increasing debt but the differences are not statistically significant. The coefficients for the subsamples are of similar size and signs, but only statistically significant for assets. To illustrate what these effects mean in perspective of infrequent illness episodes with unexpected large medical spending, we look at average OOP spending by households in the top percentile of health care spending. If this spending would be fully financed by selling productive assets, then the dynamic 
effects imply a 0.8 percent decrease in non-food consumption in the next period, and a 0.6 percent decrease in total consumption. Non-food and total consumption would decrease by 0.7 and 0.4 percent if OOP spending would be financed by borrowing.

While the follow-on effects of debt and depleting productive assets on consumption are statistically significant, they seem rather small compared to the direct effects of serious illness on income and OOP medical spending. This suggests that strategies such as borrowing and selling assets can be successful in protecting current consumption from illness induced income loss and medical costs, while the medium term costs of protecting consumption are only a fraction of the immediate costs of serious illness. However, the longer term effects might be more pronounced, especially if debt and loss of assets would inhibit households to return to their original consumption paths and the follow-on effects on consumption persist over a number of years.

\section{Conclusion}

This paper investigates the economic consequences of morbidity and mortality for the poor in urban slums of Bangladesh, the manner in which these households respond to such events, and how their most common coping strategies - borrowing and drawing on assets - affects future consumption.

We find that the economic risk stems from both medical spending and income loss. A serious illness of a household member sharply increases OOP health spending and the incidence of catastrophic spending. Moreover, a serious illness exerts a negative effect on household income for the poorest half of the sample. A death among economically active household members also leads to income loss, by reducing labour supply. Despite these non-trivial economic risks, we cannot reject 
consumption smoothing for these urban households; at least not in the short term. However, it would be short-sighted to argue that households are able to rely on informal coping strategies to deal with the economic effects of health shocks. The most prominent response to finance current needs is to borrow from money lenders and to sell productive assets. In turn, the increase in household debt-to-income ratios and the loss of productive assets has detrimental effects on future consumption.

Public health policy in Bangladesh over the last decade has focussed mainly on improving nutritional status, child malnutrition, maternity health and familyplanning services, but has been notably absent on issues regarding affordability of health care for the urban poor (e.g. Osman 2009, Rashid 2009). Our findings suggest that policies geared at providing financial protection from ill health for urban poor, such as subsidized health coverage or insurance (e.g. Hamid et al. 2011) and access to affordable credit (e.g. Islam and Maitra 2012) could contribute to reducing impoverishment and the risk of poverty traps for the urban poor due to morbidity and mortality.

Finally, we highlight two caveats to this study that warrant further research. First, while this is (to the best of our knowledge) the only study of the economic risk from morbidity and mortality that focusses specifically on poor urban areas, it is also limited in its generalizability. The analysis is based on data from urban slum communities in just one municipality in Bangladesh, for the time period 2002 to 2003. We make a case that the urban and rural contexts differ substantially in health risk, access to basic health services and financial protection from mortality and morbidity, for example through differences in occupational choices, social networks, flexibility of household labour supply and working arrangements, and informal financial markets. This calls for additional research in other municipal areas and more recent 
time periods. Second, the time span of our paper is limited to about 15 months.

Longer panel data are required to obtain a more complete understanding of the longer term effects of informal coping strategies.

\section{References}

Alderman, H., Paxson, C., 1994. Do the Poor Insure? A Synthesis of the Literature on Risk and Consumption in Developing Countries. In d. Bacha, ed. Economics in a Changing World. Vol. 4: Development, Trade and the Environment. London:Macmillan.

Ambrosius, C., Cuecuecha, A., 2013. Are remittances a substitute for credit? Carrying the financial burden of health shocks in national and transnational households. World Development, 46 (6), 143-152.

Asfaw, A., von Braun, J., 2004. Is Consumption Insured against Illness? Evidence on Vulnerability of Households to Health Shocks in Rural Ethiopia. Economic Development and Cultural Change, 53 (1), 115-129.

BBS-UNICEF, 2010. Multiple Indicator Cluster Survey 2009, 1, Technical Report, Ministry of Planning, Government of Bangladesh and United Nations Children's Fund.

Begum, S., Sen, B., 2004. Unsustainable livelihoods, health shocks and urban chronic poverty: Rickshaw Pullers as a Case study. Working Paper-46, CPRC.

Buntin, M.B., Zaslavsky, A.M., 2004. Too much ado about two-part models and transformation? Comparing methods of modeling Medicare expenditures. Journal of Health Economics, 23(3), 525-542. 
Buttenheim, A.M., 2008. The sanitation environment in urban slums: implications for child health. Population Environment, 30, 26-47.

Carrin, G., Gray, E., Almeida, J. 1999 Coping with ill health in a rickshaw puller's household in Chittagong, Bangladesh. Southeast Asian Journal of Tropical Medicine and Public Health, 30(1), 136-148.

Chetty, R., Looney, A., 2006. Consumption Smoothing and the Welfare Consequences of Social Insurance in Developing Economies. Journal of Public Economics, 90(12), 2351-2356.

De Weerdt, J., Dercon, S., 2006. Risk-Sharing Networks and Insurance Against Illness. Journal of Development Economics, 81(2), 337-356.

Dercon, S., 2002. Income Risk, Coping Strategies and Safety Nets. The World Bank Research Observer, 17(2), 141-166.

Dercon, S., Krishnan, P., 2000. In Sickness and in Health: Risk Sharing within Households in Rural Ethiopia. The Journal of Political Economy, 108(4), 688727.

Gertler, P., Gruber, J., 2002. Insuring Consumption against Illness. American Economic Review, 92(1), 51-70.

Gertler, P., Levine, D.I., Moretti, E., 2009. Do microfinance programs help families insure consumption against illness? Health Economics, 18, 257-273.

Genoni, M.E., 2012. Health shocks and consumption smoothing: evidence from Indonesia. Economic Development and Cultural Change, 60(3), 475-506. 
Günther, I., Harttgen, K., 2009. Estimating households vulnerability to idiosyncratic and covariate shocks: a novel method applied in Madagascar.World Development, 37(7), 1222-1234.

Hamid, S.A., Roberts, J., Mosley, P., 2011. Evaluating the Health Effects of Micro Health Insurance Placement: Evidence from Bangladesh. World Development, 39(3), 399-411.

Horrace, W., Oaxaca, R.L., 2006. Results on the bias and inconsistency of ordinary least squares for the linear probability model. Economics Letters, 90(3), 321-327.

IFPRI, 2009. Bangladesh: SHAHAR Dinajpur Baseline Survey, 2002-2003.

Washington, D.C.: International Food Policy Research Institute. (datasets). http://www.ifpri.org/dataset/bangladesh-3.

Islam A., Maitra P., 2012. Health shocks and consumption smoothing in rural households: does microcredit have a role to play? Journal of Development Economics, 97 (2): 232-243.

Kabir, M.A., Rahman, A., Salway, A., Pryer, J., 2000. Sickness among the urban poor: a barrier to livelihood security. Journal of International Development, 12, 707-722.

Kochar, A., 1995. Explaining Household Vulnerability to Idiosyncratic Income Shocks. American Economic Review, 85(2),159-164.

Manning, W.G., Mullahy, J., 2001. Estimating log models: to transform or not to transform? Journal of Health Economics, 20(4), 461-494.

Mihaylova, B., Briggs, A., O’Hagan, A., Thompson, S., 2011. Review of statistical methods for analyzing health care resources and costs. Health Economics, 20(8), 897-916. 
McIntyre, D., Thiede, M., Dahlgren, G., Whitehead, M., 2006. What are the economic consequences for households of illness and of paying for health care in low- and middle-income country contexts. Social Science and Medicine, 62, 858-865.

Mohanan, M., 2013. Causal effects of health shocks on consumption and debt: quasiexperimental evidence from bus accident injuries. The Review of Economics and Statistics, 95(2), 673-681.

Morduch, J., 1999. Between the State and the Market: Can Informal Insurance Patch the Safety Net? World Bank Research Observer, 14(2), 187-207.

Mottaleb, K. A., Mohanty, S., Mishra, A. K., 2015. Intra-Household Resource Allocation under Negative Income Shock: A Natural Experiment. World Development, 66 (2), 557-571.

Nguyen T.N.N., Mangyo, E., 2010. Vulnerability of households to health shocks: an Indonesian study. Bulletin of Indonesian Economic Studies, 46(2): 213-235.

Osman, F. A., 2009. Public Health, Urban Governance and the Poor in Bangladesh: Policy and Practice. Asia-Pacific Development Journal, 16(1), 27-58.

Rashid, S. F., 2009. Strategies to Reduce Exclusion among Populations Living in Urban Slum Settlements in Bangladesh. Journal of Health Population and Nutrition, 27(4), 574-86.

Santos Silva, J.M.C., Tenreyro, S., 2006. The log of gravity. The Review of Economics \& Statistics, 88(4), 641-658.

Sen, B., 2003. Drivers of Escape and Descent: Changing Household Fortunes in Rural Bangladesh. World Development, 31(3), 513-534. 
Skoufias, E., Quisumbing, A.R., 2005. Consumption insurance and vulnerability to poverty: a synthesis of the evidence from Bangladesh, Ethiopia, Mali, Mexico and Russia. The European Journal of Development Research, 17(1), 24-58.

Sparrow, R., van de Poel, E., Hadiwidjaja, G., Suryahadi, A., Warda, N. and Yumna, A., 2014. Coping with the Economic Consequences of Ill Health in Indonesia. Health Economics, 23(6), 719-728.

Townsend, R. M., 1994. Risk and Insurance in Village India. Econometrica, 62(3), 539-91.

Townsend, R. M., 1995. Consumption Insurance: An Evaluation of Risk-Bearing Systems in Low-Income Economies. Journal of Economic Perspectives, 9(3), 83102.

Wagstaff, A., 2007. The economic consequences of health shocks: evidence from Vietnam. Journal of Health Economics, 26, 82-100.

Wooldridge, J.M., 2002. Econometric Analysis of Cross Section and Panel Data. MIT Press: Cambridge. 


\section{Notes}

${ }^{1}$ On the basis of their review of studies from low and middle-income countries McIntyre et al. (2006, p. 860) provide a useful illustration of the economic consequences and potential coping mechanisms available to households when faced by health shocks. Earlier reviews of the literature on income risk and coping strategies in developing countries are provided by Alderman and Paxson (1994), Townsend (1995), Morduch (1999), and Dercon (2002).

${ }^{2}$ An exception is Wagstaff (2007) who analyses the effects of morbidity, mortality and changes in health status as measured by the body mass index (BMI) on income, medical expenditure and consumption in both urban and rural areas in Vietnam. He finds that earned income is negatively affected by health shocks, especially the death of a working-age household member, with larger proportionate effects in urban areas. The effect of other health shocks on income is not as pronounced.

${ }^{3}$ All figures in the preceding sentences are from http://data.un.org (accessed on June $11,2011)$

${ }^{4}$ For instance, corresponding figures for India in 2003 were 1 bed and 0.58 physicians per thousand persons. Source: http://data.worldbank.org/indicator/ (accessed December 19, 2013).

${ }^{5}$ In 2011 public health expenditure amounted to 36.6 percent of total health expenditure while total health expenditure was 3.7 percent of GDP. Source: http://data.worldbank.org/indicator/ (accessed December 19, 2013). ${ }^{6}$ The sample size for the survey was designed to support the detection of statistically significant changes in child stunting. Nutritional status was chosen as the key variable of interest as the objective of the program was to improve food and nutrition security (IFPRI 2009). 
${ }^{7}$ These results are not shown here but are reported in the supplemental appendix.

${ }^{8}$ In the survey context, a household is defined as a group of people who live together and take food from the 'same pot'. A household member is defined as an individual who has lived in the household for at least 12 months and at least half of the week in each week during the 12 month period.

${ }^{9}$ Based on the 2000 urban poverty line of 724.6 Bangladeshi Taka per person/month, calculated by Sen (2003) following the cost of basic needs method. This is equivalent to US $\$ 12.18$ on August 1,2002 . If we take a poverty line of US\$1 per day, then about 92 percent of the households in round 1 would classify as poor.

${ }^{10}$ The World Development Indicators estimate the urban and rural poverty headcount in 2000 at 35 and 52 percent, respectively. Source:

http://databank.worldbank.org/data/home.aspx (accessed on December 6, 2013).

${ }^{11}$ Household assets are categorised as either consumer durable (for example furniture, kitchenware, jewellery, electronics) or productive asset (for example a sewing machine, fishnet, agricultural equipment, rickshaw, boat).

${ }^{12}$ We follow a test proposed by Gertler and Gruber (2002) and Gertler et al. (2009). Unfortunately the test was inconclusive as to whether state dependence is an issue for our analysis. The intuition behind this test is that if state dependence occurs, we expected it to affect the correlation between morbidity and consumption irrespective of whether a household is budget constrained in smoothing away morbidity events. This implies a test for state dependence, by comparing different subsamples with varying (expected) ability to self-insure. For our sample we looked at the poorest and wealthiest 50 percent of households in the sample. We rank households based on two separate measures: (i) per capita household (non-medical) expenditures in wave 1 of the survey, and (ii) the monetary value of asset holdings in wave 1. However, for both 
wealth measures we cannot reject the consumption smoothing for any of the subsamples, which renders the test ineffective.

${ }^{13}$ We are aware that linear probability models could be mis-specified for the binary outcomes. Nevertheless we apply a linear specification in order to be able to control for household fixed effects. We tried fixed effects logit models as alternative, but these did not converge. Horrace and Oaxaca (2006) argue that the potential bias in linear probability models increases with the proportion of predicted probabilities that falls outside the zero to one interval. They subsequently suggest a trimming estimator by dropping those observations outside the interval and re-estimating the linear model for the remaining sample. For the self-reported coping response variables 78 to 84 percent of predicted probabilities fall within the unit interval, compared to 62 percent for the incidence of catastrophic OOP spending. The Horrace and Oaxaca trimmed estimator yields larger coefficients, yet the interpretation and conclusions remains the same. We therefore present the linear probability models in the paper, avoiding further loss of observations.

${ }^{14}$ We considered the use of days of work lost due to illness as an alternative morbidity variable, as this introduces variation in the intensity of illness. The employment module of the survey collects this information for individual household members and we constructed a variable that records the average days of work lost for household members older than 15 in the last month. The results (reported in the supplemental appendix) are robust to choice of illness variable. The coefficients differ in magnitude compared to those for the serious illness variable, which is to be expected since the units of the two variables are different. However, the sign and statistical significance are the same. Moreover, the mortality coefficients are unaffected by the change in specification. 
${ }^{15}$ In addition to the differences in outcomes across expenditure category we also estimate the effects of morbidity and mortality separately by education level (no education/some education) and type of employment (self-employed/wage worker, salaried worker, traders). In classifying these categories of vulnerability we were restricted by the sample size and therefore limited the sub-samples for comparison to two groups that are of sufficient size $(59 \%$ of household heads never attended school and $37 \%$ are self-employed). The results (reported in the supplemental appendix) seem to be similar to the estimates for those above and below median expenditure. Those who are not self-employed and have relatively higher education spend more on health care when they face a health shock. This is not unexpected and most likely reflects differences in affordability, just as we observe for wealthier households (above median expenditure). The negative effect of the death of a household member on income is mostly concentrated amongst the non-self-employed group (above median expenditure), most likely due to loss of wages/salaried workers.

${ }^{16}$ To assess possible violations of the irrelevance of independence (IIA) assumption, we estimated the MNL model for three options, by combining the Other and None categories. These seem the most likely candidates to violate the IIA, as Borrowing and Depleting assets are very distinct alternatives. The results (reported in the supplemental appendix) show that the marginal effects for depleting assets are almost identical for both models. We see only one change in the borrowing equation - the effect of higher secondary education. The coefficient is smaller and less precise. All other effects remain unchanged. This suggests that the estimates reported in the paper are not affected by violation of the IIA assumption. 
${ }^{17}$ We fix the consumption quartiles to those observed in the first panel wave since these are more likely to be exogenous to the subsequent coping behaviour than current consumption levels. 


\section{Tables}

Table 1 Household reporting to experience unexpected negative events

\begin{tabular}{|c|c|c|c|c|c|}
\hline \multirow[t]{2}{*}{ Type of shock (recall period) } & \multicolumn{3}{|c|}{ Survey round } & \multirow[t]{2}{*}{ Total } & \multirow[t]{2}{*}{$\%$} \\
\hline & 1 & 2 & 3 & & \\
\hline Death of main earner in household ${ }^{a}$ & 2 & 5 & 3 & 10 & 1.8 \\
\hline Death of other household member ${ }^{a}$ & 19 & 8 & 4 & 31 & 5.7 \\
\hline Serious injury or illness ${ }^{b}$ & 147 & 45 & 75 & 267 & 48.8 \\
\hline Loss of a regular job ${ }^{b}$ & 7 & 2 & 6 & 15 & 2.7 \\
\hline Eviction from previous residence ${ }^{b}$ & 44 & 4 & 0 & 48 & 8.8 \\
\hline Divorce or abandonment ${ }^{b}$ & 9 & 1 & 3 & 13 & 2.4 \\
\hline Major loss of crops ${ }^{b}$ & 2 & 1 & 0 & 3 & 0.5 \\
\hline Loss of livestock ${ }^{b}$ & 13 & 5 & 9 & 27 & 4.9 \\
\hline Loss of productive assets ${ }^{b}$ & 3 & 4 & 5 & 12 & 2.2 \\
\hline Loss of consumer durables ${ }^{b}$ & 17 & 1 & 2 & 20 & 3.7 \\
\hline Dowry payment ${ }^{b}$ & 5 & 3 & 6 & 14 & 2.6 \\
\hline Failure or bankruptcy of business ${ }^{b}$ & 1 & 9 & 16 & 26 & 4.8 \\
\hline Extortion by mastans/hoodlums ${ }^{c}$ & 5 & 2 & 0 & 7 & 1.3 \\
\hline Police confiscated assets ${ }^{c}$ & 1 & 0 & 4 & 5 & 0.9 \\
\hline Household member arrested ${ }^{c}$ & 3 & 1 & 5 & 9 & 1.6 \\
\hline Paid a large bribe ${ }^{\mathrm{c}}$ & 4 & 4 & 0 & 8 & 1.5 \\
\hline Long duration hartals/strikes ${ }^{\mathrm{c}}$ & 5 & 0 & 0 & 5 & 0.9 \\
\hline Rickshaw broken by picketers ${ }^{c}$ & 2 & 0 & 0 & 2 & 0.4 \\
\hline Other & 5 & 2 & 18 & 25 & 4.6 \\
\hline Total & 294 & 97 & 156 & 547 & 100.0 \\
\hline
\end{tabular}


Table 2 Households experiencing morbidity and mortality

\begin{tabular}{lcccc}
\hline Morbidity and mortality & \multicolumn{3}{c}{ Survey round } & Total \\
& 1 & 2 & 3 & \\
\hline Death of a household member & 21 & 13 & 7 & 41 \\
Serious illness of a household member & $(3.6)$ & $(2.3)$ & $(1.3)$ & \\
& 147 & 45 & 75 & 267 \\
Total & $(25.1)$ & $(7.9)$ & $(13.6)$ & \\
& 168 & 58 & 82 & 308 \\
\hline Number of households & $(28.7)$ & $(10.2)$ & $(14.8)$ & \\
\hline Notes: Figures in parentheses indicate percentage of households. Recall periods in the \\
first year are 2 years for a death and 1 year for serious illness of a household member. \\
In the second and third survey rounds the recall period for both variables is the six \\
months preceding the surveys.
\end{tabular}


Table 3 Main coping response of households affected by morbidity and mortality

\begin{tabular}{lcc}
\hline Coping strategy & Frequency & Percent \\
\hline Deplete assets and savings & & \\
Sold/mortgaged productive asset & 10 & 3.2 \\
Sold/mortgaged consumer durables & 8 & 2.6 \\
Used savings & 8 & 2.6 \\
Borrowing & & \\
Took loan from NGOs/institution/employer & 22 & 7.1 \\
Took loan from mahajan (moneylender) & 94 & 30.5 \\
Other strategies & & \\
Reduced food consumption & 10 & 3.2 \\
Sent non-working household member to work & 3 & 1.0 \\
Took help from others & 18 & 5.8 \\
Other (non-specified) & 14 & 4.5 \\
None & 121 & 39.3 \\
\hline Total & 308 & 100.0 \\
\hline
\end{tabular}

Notes: Reported frequencies are conditional on households reporting a shock. 
Table 4 Descriptive statistics of main variables

\begin{tabular}{|c|c|c|c|c|c|c|}
\hline \multirow[b]{2}{*}{ Variable } & \multicolumn{2}{|c|}{ Round 1} & \multicolumn{2}{|c|}{ Round 2} & \multicolumn{2}{|c|}{ Round 3} \\
\hline & Mean & SD & Mean & SD & Mean & SD \\
\hline Per capita earned income in last month* & 735.65 & 476.37 & 686.60 & 493.09 & 709.99 & 588.46 \\
\hline Per capita unearned income in last month* & 54.31 & 158.39 & 51.11 & 221.66 & 57.47 & 169.46 \\
\hline Per capita non-food consumption in last week* & 85.29 & 136.64 & 78.67 & 130.86 & 94.54 & 324.12 \\
\hline Per capita OOP health expenses in last week* & 10.92 & 33.47 & 11.22 & 31.90 & 13.15 & 44.31 \\
\hline Share of OOP health expenses of total consumption & 0.05 & 0.08 & 0.06 & 0.10 & 0.05 & 0.10 \\
\hline Outstanding loans* & 5135.02 & 13274.56 & 6394.13 & 22513.61 & 7437.33 & 17431.87 \\
\hline Debt to income ratio & 1.66 & 3.27 & 2.43 & 12.93 & 3.19 & 10.25 \\
\hline Total value of all assets* & 18862.55 & 34099.29 & 19943.63 & 35112.46 & 21818.92 & 37928.71 \\
\hline Total value of productive assets* & 1620.61 & 4730.29 & 2216.93 & 8198.14 & 2764.02 & 8495.13 \\
\hline Per capita hours worked in last week & 21.51 & 13.95 & 20.34 & 13.87 & 20.61 & 12.80 \\
\hline Head completed secondary school & 0.05 & 0.21 & 0.05 & 0.21 & 0.05 & 0.21 \\
\hline Head completed higher secondary school & 0.01 & 0.12 & 0.01 & 0.11 & 0.01 & 0.11 \\
\hline Observations & \multicolumn{2}{|c|}{585} & \multicolumn{2}{|c|}{567} & \multicolumn{2}{|c|}{553} \\
\hline
\end{tabular}

Notes: ${ }^{(*)}$ Figures are in Bangladeshi Taka (BDT); 1 Euro $=58.18$ BDT on August 1, 2002. 
Table 5 Effects of serious illness and death of household members on per capita household consumption and income

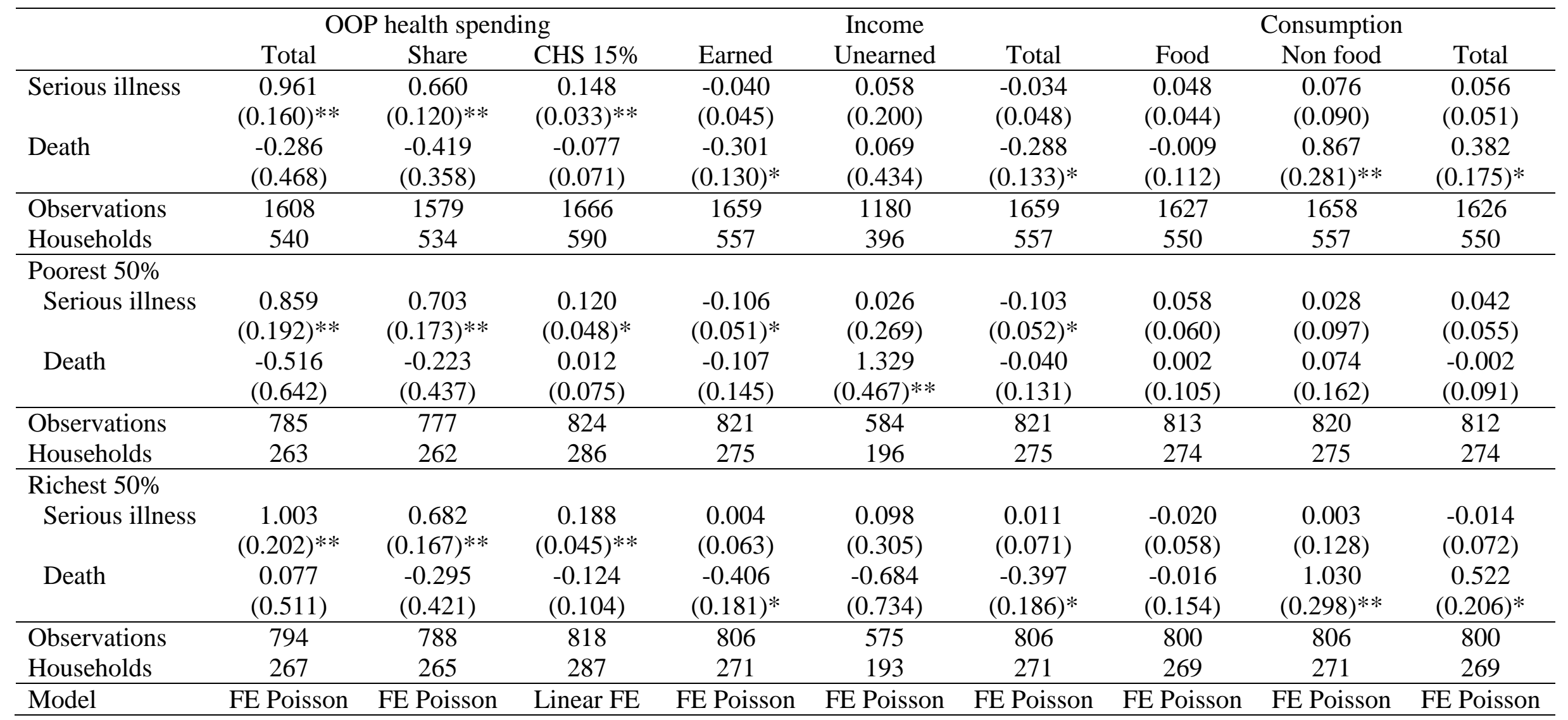

Notes: Table shows coefficients from Poisson models with household fixed effects and fixed effects linear probability models. Other covariates omitted from the table include other shocks, household size, demographic composition of the household and time-community interaction terms. Statistical significance:,$+{ }^{*}$ and $* *$ indicate significance at the $10 \%, 5 \%$ and $1 \%$ respectively. Robust standard errors in brackets. 
Table 6 Coping strategies for serious illness and death of household members

\begin{tabular}{|c|c|c|c|c|c|c|c|}
\hline & \multicolumn{3}{|c|}{ Self-reported coping strategies } & \multicolumn{4}{|c|}{ Economic buffers and indebtedness } \\
\hline & $\begin{array}{c}\text { Deplete assets } \\
\text { and savings }\end{array}$ & Borrowing & Other & Labour supply & All assets & $\begin{array}{l}\text { Productive } \\
\text { assets }\end{array}$ & $\begin{array}{l}\text { Debt to income } \\
\text { ratio }\end{array}$ \\
\hline \multirow[t]{2}{*}{ Serious illness } & 0.268 & 0.613 & -0.084 & -0.075 & 0.011 & -0.100 & 0.382 \\
\hline & $(0.104)^{*}$ & $(0.129)^{* *}$ & $(0.115)$ & $(0.041)$ & $(0.023)$ & $(0.098)$ & $(0.164)^{*}$ \\
\hline \multirow[t]{2}{*}{ Death } & 0.230 & 0.258 & -0.038 & -0.175 & -0.004 & -0.316 & 0.016 \\
\hline & $(0.101)^{*}$ & $(0.211)$ & $(0.147)$ & $(0.100)$ & $(0.034)$ & $(0.281)$ & $(0.303)$ \\
\hline Observations & 477 & 477 & 477 & 1653 & 1654 & 909 & 1427 \\
\hline Households & 345 & 345 & 345 & 555 & 555 & 304 & 484 \\
\hline \multicolumn{8}{|l|}{ Poorest $50 \%$} \\
\hline \multirow[t]{2}{*}{ Serious illness } & 0.246 & 0.763 & 0.250 & -0.107 & -0.036 & -0.415 & 0.624 \\
\hline & $(0.172)$ & $(0.156)^{* *}$ & $(0.209)$ & $(0.060)$ & $(0.032)$ & $(0.136)^{* *}$ & $(0.250)^{*}$ \\
\hline \multirow{2}{*}{ Death } & 0.375 & 0.543 & -0.255 & -0.076 & 0.028 & 0.050 & -0.200 \\
\hline & $(0.182)^{*}$ & $(0.240)^{*}$ & $(0.335)$ & $(0.166)$ & $(0.038)$ & $(0.247)$ & $(0.425)$ \\
\hline Observations & 239 & 239 & 239 & 818 & 818 & 491 & 710 \\
\hline Households & 171 & 171 & 171 & 274 & 274 & 164 & 241 \\
\hline \multicolumn{8}{|l|}{ Richest 50\% } \\
\hline \multirow[t]{2}{*}{ Serious illness } & 0.107 & 0.453 & -0.136 & -0.086 & 0.028 & -0.122 & 0.154 \\
\hline & $(0.170)$ & $(0.297)$ & $(0.201)$ & $(0.062)$ & $(0.032)$ & $(0.168)$ & $(0.199)$ \\
\hline \multirow[t]{2}{*}{ Death } & -0.164 & -0.235 & 0.140 & -0.257 & -0.044 & -0.906 & 0.319 \\
\hline & $(0.182)$ & $(0.344)$ & $(0.221)$ & $(0.118)^{*}$ & $(0.055)$ & $(0.524)$ & $(0.300)$ \\
\hline Observations & 229 & 229 & 229 & 803 & 806 & 415 & 707 \\
\hline Households & 167 & 167 & 167 & 270 & 271 & 139 & 239 \\
\hline Model & Linear FE & Linear FE & Linear FE & FE Poisson & FE Poisson & FE Poisson & FE Poisson \\
\hline
\end{tabular}

Notes: Table shows coefficients from Poisson models with household fixed effects and fixed effects linear probability models. Other covariates omitted from the table include other shocks, household size, demographic composition of the household and time-community interaction terms.

For self-reported coping strategies the sample is restricted to households that reported a shock in the respective survey round.

Statistical significance:,$+{ }^{*}$ and $* *$ indicate significance at the $10 \%, 5 \%$ and $1 \%$ respectively. Robust standard errors in brackets. 
Table 7 Determinants of choice of coping strategy in response to serious illness

\begin{tabular}{lcccc}
\hline & Deplete assets & Borrowing & Other & None \\
\hline Age household head & 0.0002 & 0.004 & -0.002 & -0.002 \\
Male household head & $(0.002)$ & $(0.002)$ & $(0.002)$ & $(0.002)$ \\
& -0.033 & 0.112 & -0.052 & -0.027 \\
Household size & $(0.058)$ & $(0.097)$ & $(0.062)$ & $(0.093)$ \\
Head completed & -0.0001 & -0.018 & 0.001 & 0.017 \\
Primary school & $(0.009)$ & $(0.018)$ & $(0.011)$ & $(0.019)$ \\
\multirow{2}{*}{ Secondary school } & & & & \\
\multirow{2}{*}{ Higher secondary school } & -0.032 & 0.103 & 0.020 & -0.090 \\
Quartile & $(0.061)$ & $(0.103)$ & $(0.072)$ & $(0.105)$ \\
2 & -1.085 & 0.545 & 0.071 & 0.470 \\
& $(0.200)^{* *}$ & $(0.146)^{* *}$ & $(0.141)$ & $(0.156)^{* *}$ \\
3 & -0.941 & 1.172 & -1.486 & 1.255 \\
& $(0.181)^{* *}$ & $(0.253)^{* *}$ & $(0.209)^{* *}$ & $(0.220)^{* *}$ \\
4 & 0.011 & -0.033 & 0.073 & -0.051 \\
& $(0.046)$ & $(0.085)$ & $(0.058)$ & $(0.086)$ \\
Round & 0.024 & 0.105 & 0.008 & -0.138 \\
2 & $(0.044)$ & $(0.089)$ & $(0.054)$ & $(0.083)+$ \\
3 & 0.108 & -0.127 & 0.059 & -0.040 \\
& $(0.062)+$ & $(0.084)$ & $(0.062)$ & $(0.091)$ \\
\hline Pseudo R-squared & & & & \\
Observations & 0.032 & -0.031 & 0.066 & -0.068 \\
\hline
\end{tabular}

Notes: Table shows marginal effects from a multinomial logit model.

Statistical significance:,$+{ }^{*}$ and $* *$ indicate significance at the $10 \%, 5 \%$ and $1 \%$ respectively. Robust standard errors in brackets. 
Table 8 Effects of lagged debt to income ratio and assets on per capita household consumption

\begin{tabular}{lccc}
\hline & Food & Non food & Total \\
\hline Full sample & & & \\
Debt to income ratio & 0.003 & -0.015 & -0.009 \\
& $(0.004)$ & $(0.007)^{*}$ & $(0.004)^{*}$ \\
Productive assets $(\times 1000)$ & 0.003 & 0.006 & 0.004 \\
& $(0.002)$ & $(0.002)^{* *}$ & $(0.002)^{* *}$ \\
Observations & 1056 & 1078 & 1054 \\
Households & 528 & 539 & 527 \\
\hline Poorest 50\% & & & \\
Debt to income ratio & 0.013 & -0.025 & -0.007 \\
& $(0.019)$ & $(0.027)$ & $(0.017)$ \\
Productive assets $(\times 1000)$ & 0.005 & 0.006 & 0.004 \\
& $(0.02)$ & $(0.06)$ & $(0.03)$ \\
Observations & 524 & 534 & 522 \\
Households & 262 & 267 & 261 \\
\hline Wealthiest 50\% & & & \\
Debt to income ratio & 0.001 & -0.013 & -0.007 \\
& $(0.003)$ & $(0.008)$ & $(0.005)$ \\
Productive assets $(\times 1000)$ & 0.004 & 0.005 & 0.005 \\
& $(0.002)^{*}$ & $(0.002)^{* *}$ & $(0.002)^{* *}$ \\
Observations & 520 & 524 & 520 \\
Households & 260 & 262 & 260
\end{tabular}

Notes: Table shows coefficients from Poisson models with household fixed effects. Other covariates omitted from the table include other shocks, household size, demographic composition of the household and time-community interaction terms. Statistical significance:,$+{ }^{*}$ and $* *$ indicate significance at the $10 \%, 5 \%$ and $1 \%$ respectively. Robust standard errors in brackets. 


\section{Supplemental appendix (not for publication but available online)}

Table A1 Test for attrition bias: probability of dropping out of the sample

\begin{tabular}{|c|c|c|c|c|c|}
\hline & (1) & (2) & (3) & (4) & (5) \\
\hline \multirow[t]{2}{*}{ Age household head } & -0.004 & -0.004 & -0.005 & -0.005 & -0.012 \\
\hline & $(0.007)$ & $(0.007)$ & $(0.007)$ & $(0.007)$ & $(0.007)$ \\
\hline \multirow[t]{2}{*}{ Male household head } & -0.171 & -0.174 & -0.175 & -0.221 & -0.184 \\
\hline & $(0.224)$ & $(0.225)$ & $(0.226)$ & $(0.219)$ & $(0.237)$ \\
\hline Head completed & 0.413 & 0.407 & 0.418 & 0.408 & 0.407 \\
\hline \multirow[t]{2}{*}{ Primary school } & $(0.264)$ & $(0.263)$ & $(0.264)$ & $(0.267)$ & $(0.265)$ \\
\hline & 0.252 & 0.263 & 0.245 & 0.168 & 0.244 \\
\hline \multirow[t]{2}{*}{ Secondary school } & $(0.371)$ & $(0.377)$ & $(0.376)$ & $(0.367)$ & $(0.363)$ \\
\hline & 0.451 & 0.439 & 0.416 & 0.349 & 0.468 \\
\hline \multirow[t]{2}{*}{ Higher secondary school } & $(0.580)$ & $(0.613)$ & $(0.594)$ & $(0.567)$ & $(0.585)$ \\
\hline & $-0.145^{*}$ & $-0.153 *$ & $-0.145^{*}$ & -0.121 & -0.117 \\
\hline \multirow[t]{2}{*}{ Household size } & $(0.070)$ & $(0.069)$ & $(0.069)$ & $(0.067)$ & $(0.070)$ \\
\hline & & 0.199 & & & \\
\hline \multirow[t]{2}{*}{ Serious illness } & & $(0.189)$ & & & \\
\hline & & 0.298 & & & \\
\hline \multirow[t]{2}{*}{ Death } & & $(0.439)$ & & & \\
\hline & & & 0.001 & & \\
\hline \multirow[t]{2}{*}{ OOP health spending } & & & $(0.002)$ & & \\
\hline & & & & 0.0002 & \\
\hline \multirow[t]{2}{*}{ Earned income } & & & & $(0.0002)$ & \\
\hline & & & & -0.00003 & \\
\hline \multirow[t]{2}{*}{ Unearned income } & & & & $(0.0004)$ & \\
\hline & & & & & 0.001 \\
\hline \multirow[t]{2}{*}{ Food spending } & & & & & $(0.001)$ \\
\hline & & & & & -0.001 \\
\hline \multirow[t]{2}{*}{ Non-food spending } & & & & & $(0.001)$ \\
\hline & $-0.766^{*}$ & $-0.821 *$ & $-0.770^{*}$ & $-0.938 *$ & -0.677 \\
\hline \multirow[t]{2}{*}{ Constant } & $(0.364)$ & $(0.378)$ & $(0.365)$ & $(0.395)$ & $(0.418)$ \\
\hline & -0.004 & -0.004 & -0.005 & -0.005 & -0.012 \\
\hline Pseudo R-squared & 0.048 & 0.055 & 0.050 & 0.054 & 0.054 \\
\hline Observations & 585 & 585 & 585 & 585 & 573 \\
\hline
\end{tabular}

Notes: Probit estimates. The explanatory variables are taken for the first survey wave only. The outcome variable is a dummy variable that takes value one if a household is not observed in all three survey waves.

Statistical significance:,$+{ }^{*}$ and $* *$ indicate significance at the $10 \%, 5 \%$ and $1 \%$ respectively. Robust standard errors in brackets. 
Table A2. Effects of serious illness and death of household members: Using average work days lost to illness for working age household members (age>15) in last month

\begin{tabular}{lccccccccc}
\hline & \multicolumn{3}{c}{ OOP health spending } & \multicolumn{3}{c}{ Income } & \multicolumn{2}{c}{ Consumption } \\
& Total & Share & CHS 15\% & Earned & Unearned & Total & Food & Non food & Total \\
\hline Days lost to illness & 0.107 & 0.069 & 0.023 & -0.009 & 0.034 & -0.004 & -0.007 & 0.041 & 0.018 \\
& $(0.027)^{* *}$ & $(0.018)^{* *}$ & $(0.005)^{* *}$ & $(0.010)$ & $(0.033)$ & $(0.011)$ & $(0.008)$ & $(0.035)$ & $(0.022)$ \\
Death & -0.486 & -0.568 & -0.092 & -0.295 & 0.040 & -0.283 & -0.015 & 0.856 & 0.375 \\
& $(0.567)$ & $(0.380)$ & $(0.073)$ & $(0.128)^{*}$ & $(0.439)$ & $(0.132)^{*}$ & $(0.114)$ & $(0.274)^{* *}$ & $(0.173)^{*}$ \\
\hline Observations & 1608 & 1579 & 1666 & 1659 & 1180 & 1659 & 1627 & 1658 & 1626 \\
Households & 540 & 534 & 590 & 557 & 396 & 557 & 550 & 557 & 550 \\
\hline Model & FE Poisson & FE Poisson & Linear FE & FE Poisson & FE Poisson & FE Poisson & FE Poisson & FE Poisson & FE Poisson \\
\hline
\end{tabular}

Notes: Table shows coefficients from Poisson models with household fixed effects and linear fixed effects models. Other covariates omitted from the table include other shocks, household size, demographic composition of the household and time-community interaction terms. Statistical significance: $+{ }^{*}$ and $* *$ indicate significance at the $10 \%, 5 \%$ and $1 \%$ respectively. Robust standard errors in brackets. 
Table A3. Effects of serious illness and death of household members: By employment type (self-employed vs not self-employed)

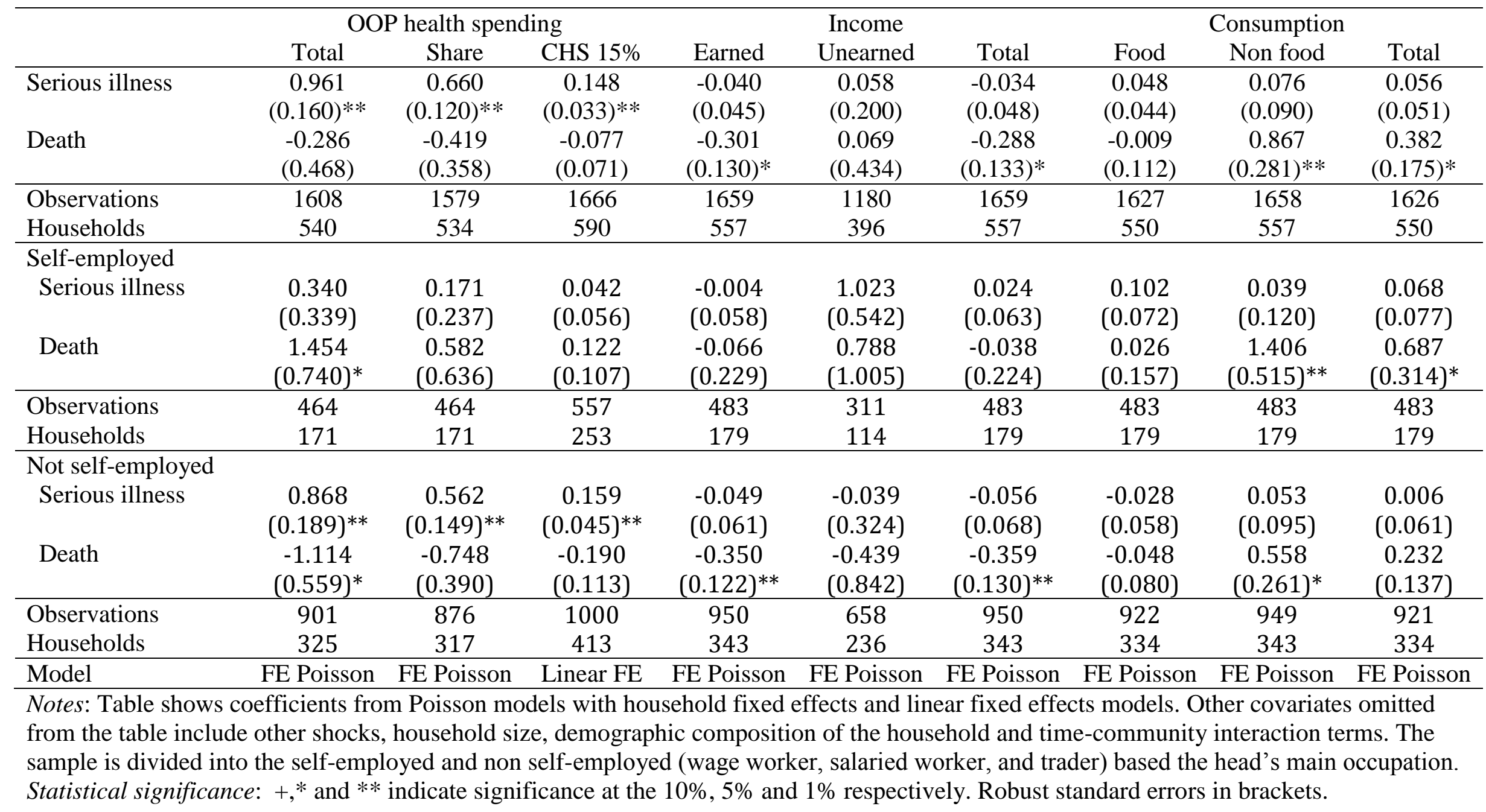


Table A4. Effects of serious illness and death of household members: By education level (never attended primary level vs some education)

\begin{tabular}{lccccccccc}
\hline & \multicolumn{3}{c}{ OOP health spending } & \multicolumn{3}{c}{ Income } & \multicolumn{2}{c}{ Consumption } \\
& Total & Share & CHS 15\% & Earned & Unearned & Total & Food & Non food & Total \\
\hline Serious illness & 0.961 & 0.660 & 0.148 & -0.040 & 0.058 & -0.034 & 0.048 & 0.076 & 0.056 \\
& $(0.160)^{* *}$ & $(0.120)^{* *}$ & $(0.033)^{* *}$ & $(0.045)$ & $(0.200)$ & $(0.048)$ & $(0.044)$ & $(0.090)$ & $(0.051)$ \\
Death & -0.286 & -0.419 & -0.077 & -0.301 & 0.069 & -0.288 & -0.009 & 0.867 & 0.382 \\
& $(0.468)$ & $(0.358)$ & $(0.071)$ & $(0.130)^{*}$ & $(0.434)$ & $(0.133)^{*}$ & $(0.112)$ & $(0.281)^{* *}$ & $(0.175)^{*}$ \\
\hline Observations & 1608 & 1579 & 1666 & 1659 & 1180 & 1659 & 1627 & 1658 & 1626 \\
Households & 540 & 534 & 590 & 557 & 396 & 557 & 550 & 557 & 550 \\
\hline No education & & & & & & & & & \\
Serious illness & 0.839 & 0.670 & 0.153 & -0.050 & -0.015 & -0.049 & 0.042 & 0.005 & 0.015 \\
& $(0.191)^{* *}$ & $(0.163)^{* *}$ & $(0.046)^{* *}$ & $(0.054)$ & $(0.246)$ & $(0.055)$ & $(0.060)$ & $(0.103)$ & $(0.064)$ \\
Death & 0.270 & -0.224 & 0.017 & -0.257 & -0.325 & -0.274 & -0.086 & 1.359 & 0.551 \\
& $(0.497)$ & $(0.305)$ & $(0.035)$ & $(0.110)^{*}$ & $(0.537)$ & $(0.110)^{*}$ & $(0.067)$ & $(0.369)^{* *}$ & $(0.226)^{*}$ \\
\hline Observations & 930 & 907 & 968 & 970 & 688 & 970 & 944 & 969 & 943 \\
Households & 313 & 308 & 345 & 326 & 231 & 326 & 320 & 326 & 320 \\
\hline Some education & & & & & & & & \\
Serious illness & 1.032 & 0.646 & 0.133 & -0.006 & 0.238 & -0.006 & 0.061 & 0.087 & 0.082 \\
& $(0.219)^{* *}$ & $(0.177)^{* *}$ & $(0.050)^{* *}$ & $(0.068)$ & $(0.290)$ & $(0.075)$ & $(0.061)$ & $(0.151)$ & $(0.089)$ \\
Death & -0.626 & -0.558 & -0.155 & -0.326 & 0.467 & -0.286 & 0.049 & 0.166 & 0.088 \\
& $(0.461)$ & $(0.409)$ & $(0.118)$ & $(0.213)$ & $(0.466)$ & $(0.226)$ & $(0.173)$ & $(0.265)$ & $(0.191)$ \\
\hline Observations & 678 & 672 & 698 & 689 & 492 & 689 & 683 & 689 \\
Households & 227 & 226 & 245 & 231 & 165 & 231 & 230 & 231 & 230 \\
\hline Model & FE Poisson & FE Poisson & Linear FE & FE Poisson & FE Poisson & FE Poisson & FE Poisson & FE Poisson & FE Poisson \\
\hline
\end{tabular}

Notes: Table shows coefficients from Poisson models with household fixed effects and linear fixed effects models. Other covariates omitted from the table include other shocks, household size, demographic composition of the household and time-community interaction terms. The sample is divided into households where the head has never attended primary level and some education.

Statistical significance: $+{ }^{*}$ and $* *$ indicate significance at the $10 \%, 5 \%$ and $1 \%$ respectively. Robust standard errors in brackets. 
Table A5. Determinants of choice of coping strategy in response to serious illness:

Combining categories None and Other

\begin{tabular}{|c|c|c|c|}
\hline & Deplete assets & Borrowing & None/Other \\
\hline \multirow[t]{2}{*}{ Age household head } & 0.0002 & 0.004 & -0.004 \\
\hline & $(0.002)$ & $(0.002)$ & $(0.003)$ \\
\hline \multirow[t]{2}{*}{ Male household head } & -0.033 & 0.110 & -0.078 \\
\hline & $(0.058)$ & $(0.097)$ & $(0.100)$ \\
\hline \multirow[t]{2}{*}{ Household size } & -0.0001 & -0.018 & 0.018 \\
\hline & $(0.009)$ & $(0.018)$ & $(0.018)$ \\
\hline \multicolumn{4}{|l|}{ Head completed } \\
\hline \multirow[t]{2}{*}{ Primary school } & -0.033 & 0.102 & 0.070 \\
\hline & $(0.061)$ & $(0.103)$ & $(0.108)$ \\
\hline \multirow[t]{2}{*}{ Secondary school } & -1.065 & 0.518 & $0.547 * *$ \\
\hline & $(0.196)^{* *}$ & $(0.143)^{* *}$ & $(0.170)$ \\
\hline \multirow[t]{2}{*}{ Higher secondary school } & -1.071 & 0.424 & -0.646 \\
\hline & $(0.202)^{* *}$ & $(0.258)$ & $(0.228)^{*}$ \\
\hline \multicolumn{4}{|l|}{ Quartile } \\
\hline \multirow[t]{2}{*}{2} & 0.011 & -0.035 & 0.024 \\
\hline & $(0.046)$ & $(0.085)$ & $(0.088)$ \\
\hline \multirow[t]{2}{*}{3} & 0.024 & 0.105 & -0.129 \\
\hline & $(0.044)$ & $(0.089)$ & $(0.088)$ \\
\hline \multirow[t]{2}{*}{4} & 0.108 & -0.123 & 0.015 \\
\hline & $(0.062)+$ & $(0.085)$ & $(0.092)$ \\
\hline \multicolumn{4}{|l|}{ Round } \\
\hline \multirow[t]{2}{*}{2} & 0.033 & -0.031 & -0.002 \\
\hline & $(0.064)$ & $(0.082)$ & $(0.088)$ \\
\hline \multirow[t]{2}{*}{3} & -0.062 & 0.098 & -0.035 \\
\hline & $(0.034)+$ & $(0.071)$ & $(0.072)$ \\
\hline Pseudo R-squared & 0.0479 & & \\
\hline Observations & 261 & & \\
\hline
\end{tabular}

Notes: Table shows marginal effects from a multinomial logit model.

Statistical significance:,$+{ }^{*}$ and $* *$ indicate significance at the $10 \%, 5 \%$ and $1 \%$ respectively. Robust standard errors in brackets. 